\title{
Power Matching and Energy Efficiency Improvement of Hydraulic Excavator Driven with Speed and Displacement Variable Power Source
}

\author{
Lei Ge, Long Quan*, Xiaogang Zhang, Zhixin Dong and Jing Yang
}

\begin{abstract}
Mobile machinery energy efficiency and emission pollution are the national and worldwide issues. This paper contributes in solving these problems by applying a speed variable power source. Unfortunately, almost all of the speed variable systems have the dynamic response problem when the motor starts with full load or heavy load. To address this problem, a hydraulic accumulator is used to balance the load of the power source for assisting starting of the motor and a matching method combined with speed and displacement control of the pump is proposed to improve the energy efficiency and dynamic performance simultaneously under different working conditions. Also, the power source/valve combined control strategy of an independent metering system is designed to realize flow matching of the whole system. Firstly, a test system is established to study the dynamic performance and energy efficiency of the speed variable power source with an auxiliary accumulator. Working performance and energy consumption of the power source under different rotating speeds and different loads are studied. And then, the hydraulic excavator test rig with the proposed system is constructed. Furthermore, the working performance of the excavator with the speedfixed and speed-variable strategy are studied comparatively. Results show that, compared with fixed-speed strategy, the electric power consumption during the idle period and partial load condition can be reduced about $2.05 \mathrm{~kW}$ and $1.37 \mathrm{~kW}$. The energy efficiency of speed variable power source is about $40 \%-71 \%$, which is higher than that of the fixed-speed power source by $3 \%-10 \%$.
\end{abstract}

Keywords: Hydraulic excavator, Power matching, Speed variable, Energy efficiency

\section{Introduction}

As the main construction machinery, hydraulic excavator is widely used in earthwork construction field, due to their small size-to-power ratio, compact structure and big actuation forces. In the excavator, a displacement variable pump driven by a diesel engine is normally used as power source, and a set of four-sides spool valves are used to control the actuators. In such systems, one or two pumps supplied oil to more than four actuators and

\footnotetext{
*Correspondence: quanlong@tyut.edu.cn

Key Lab of Advanced Transducers and Intelligent Control System

of Ministry of Education, Taiyuan University of Technology,

Taiyuan 030024, China
}

the flow distributing by throttling caused large energy consumption.

Ref. [1] shows that the energy efficiency of the pump is about $87 \%$, the efficiency of hydraulic control system is only $30 \%$, the efficiency of the mechanical system is about $90 \%$, thus the energy consumption for working is only $23 \%$ of the engine output. Besides, the average energy efficiency of the engine is only about $35 \%$, the energy efficiency of the whole machine is very low and there is serious emission pollution [2,3]. This problem not only exists in hydraulic excavators, but also the common problems of other engineering equipment. Thus, improving the energy efficiency and reducing emission has been the research focus in this field. 
Considering the energy transfer chain, there are two ways to improve the energy efficiency of hydraulic excavator: one is to improve load-engine matching performance, another is to reduce the throttling loss.

In the conventional excavator system, the operating point of its engine should meet the needs of load power, which varies widely when the excavator works [4]. Thus, the engine often works under partial load condition, during which the energy efficiency is low. Many research efforts on these issues of the excavator have been undertaken. A conventional way to improve the efficiency of the diesel engine is adjusting the engine speed by the operator according to load condition [5]. Yang proposed a diesel engine cylinder deactivation technology by cutting off the fuel supply to one or two of the engine cylinder [6]. However, these two ways can only improve the economy of diesel engine by mechanical stepped speed changing system and it is only effectively in light load. In order to global improve the engine efficiency, the hybrid technology, in which a hydraulic motor combined with accumulator or electric motor/generator is used as the auxiliary power unit, is proposed and it can downsize the engine power also [7, 8]. Kim et al. [9] studied this hybrid system and proposed an algorithm based on the equivalent fuel minimization strategy (ECMS) to analyze the behavior of the co-state of the optimal control problem. Lin et al. $[10,11]$ proposed a boom potential energy regeneration system for a hybrid hydraulic excavator. The test results showed that an estimated $45 \%$ of the total potential energy could be regenerated. Shen et al. [12, 13] studied a hydraulic hybrid excavator based on common pressure rail in which the throttling loss was eliminated completely.

In mobile fluid power systems, several actuators are connected to one common pump. The pressure level and flow demand of one actuator will normally vary considerably during a duty cycle. One obvious way of meeting the demand of energy efficiency is to make use of load sensing, negative control and positive control technology [14-16]. However, in these systems, a four-side spool valve is used to control the actuator, which causes large throttling loss. Some theses attempt to deal with this problem by using an independent metering in and metering out system for controlling the excavator hydraulic actuators. And this is also one of the research hotspots in valve controlled systems $[17,18]$. Sitte et al. [19] introduced the structure of the independent metering system, and given an examination for mobile applications. $\mathrm{Xu}$ et al. and Quan et al. studied the pump/valves coordinate control of the independent metering system for excavator [20-22]. Shi et al. [23] proposed a velocity and position control system based on independent metering system for a hydraulic excavator.
Although many technologies have been made to improve the energy efficiency of the hydraulic excavator, such as hybrid technology. However, the energy efficiency of the engine is not higher than $40 \%$ and the emissions can not be eliminated completely. This paper proposes an advanced construction machine configuration named electric excavator, in which a frequency conversion electric motor is used to drive a displacement variable pump. As a certain operation point can be supplied by different combinations of driving speed and pump displacement, intelligent control strategies can address major issues like energy efficiency, process dynamics and noise level in hydraulic excavators [24-26]. Yan et al. [27] studied the noise of the speed and displacement variable power source. Roosen et al. [28] studied the energy optimization of hydraulic pump system, and the design process was presented by using the "Parker-Drive-Creator" software. In this paper, a control method based on the segmented speed and continuous displacement control of the pump is proposed to improve the energy efficiency and dynamic performance simultaneously under different working conditions. And also, an accumulator is introduced to the pump inlet port to further improve the system dynamic response performance when the electric motor starts with full load or heavy load. Furthermore, an independent metering in and metering out system is used to reduce the throttling loss.

The paper is organized as follows. Section 2 presents the structure and principle of the electric excavator system with independent metering in and metering out system. The dynamic performance and energy consumption characteristic of power source which consists of speed variable electric motor and displacement variable pump based on mathematical model and experiment results in Section 3. Section 4 concentrates on the controller design. Section 5 provides the experimental results. Finally, conclusions are drawn in Section 6.

\section{Working Principle of Electro-hydraulic Excavator System}

Hydraulic excavator is a typical multiple-actuators construction machine, which has 6 actuators, e.g., swing motor, boom cylinder, arm cylinder, bucket cylinder, left and right traveler motors. In this paper, the boom, arm and bucket cylinders are selected to validate the proposed system. Figure 1 gives the principle of electric excavator with independent metering in and metering out system proposed in this paper.

As shown in Figure 1, a speed variable inverter motor is used to drive an electric displacement and pressure variable pump for controlling the flow rate and pressure of the system. And,an independent metering in and metering out system is used to distribute the flow to the actuators. 


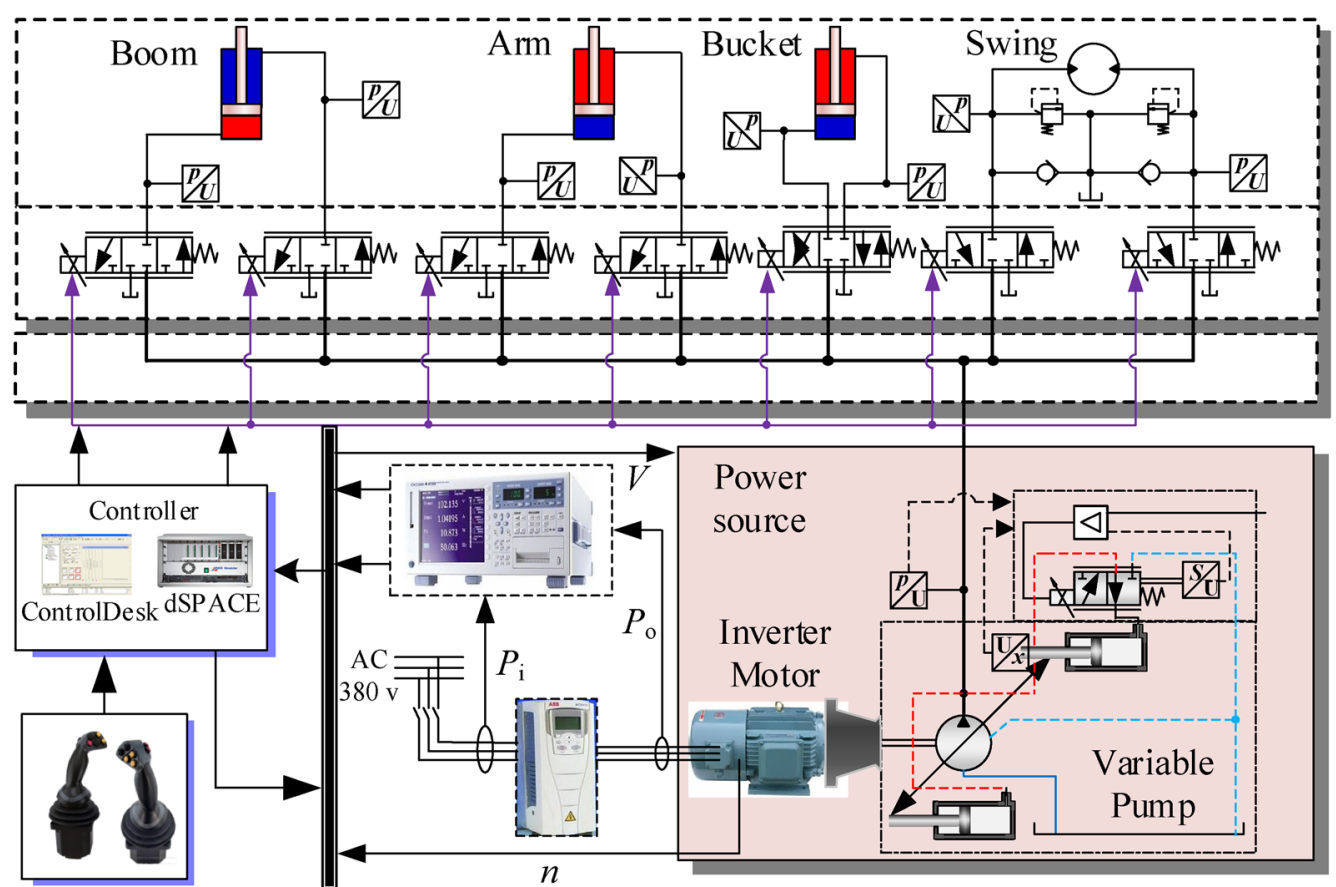

Figure 1 Working principle of electro-hydraulic excavator

And also, the boom cylinder, arm cylinder and swing motor are controlled by the independent metering in and metering out system, and bucket cylinder is controlled by a traditional three-position four-way proportional valve. And, in the system, some displacement sensors are installed in the actuators to detect the displacement and velocity, and some pressure sensors to detect the pressure inside the actuators and pump port, the power sensor and rotating speed sensor on the motor to detect the electric power and rotating speed.

The proposed system works as below: the controller takes in the inputs of joystick and the measured quantities such as pressures, powers, displacements, flow and speed of the motor. And then the controller analysis the demand automatically and output the voltage signals directly applied to the converter motor, pump and valves according to the set strategy.

The core of the research work is to improve the energy efficiency of the power source and to reduce the throttling loss of the hydraulic system, under the premise of ensuring dynamic characteristics. In the following, these two sections are described in detail.

\section{Dynamic Response and Energy Efficiency of Electro-hydraulic Power Source}

The degree of freedom of speed and displacement variable pumps can be used to adjust the operation points of the electric drive and the hydraulic pump to maximize the overall energy efficiency. And the process dynamics is determined by the electric motor and pump.

\subsection{Dynamic Response}

For the speed variable and displacement variable power source, its theoretical output flow rate can be described as Eq. (1):

$$
q=n \cdot \beta \cdot V_{\mathrm{dmax}},
$$

where $n$ stands for the rotating speed of the electric motor and the pump, $\beta$ is the ratio of real displacement to the maximum displacement, $V_{\mathrm{dmax}}$ is the maximum displacement of the pump.

The moment equilibrium equation of the electric motor can be written as Eq. (2):

$$
T_{\mathrm{m}}-T_{\mathrm{L}}-T_{\mathrm{f}}=J \frac{\mathrm{d} n}{\mathrm{~d} t}+B \cdot n,
$$

where $T_{\mathrm{m}}$ is electromagnetic torque of electric motor, $T_{\mathrm{L}}$ is load torque mainly pump's operating torque, $T_{\mathrm{f}}$ is the torque independent with rotating speed, $J$ is the moment of inertia, $B$ is damping coefficient.

The pump's operating torque $T_{\mathrm{L}}$ is proportional to the pressure difference that the pump encounters, due to the law of energy conservation. And it can be written as Eq. (3): 


$$
T_{\mathrm{L}}=\frac{\Delta p_{\mathrm{p}} \cdot \beta \cdot V_{\mathrm{dmax}}}{2 \pi \eta_{\mathrm{p}}},
$$

where $\Delta p_{\mathrm{p}}$ is the pressure difference of the pump, $\eta_{\mathrm{p}}$ is the total energy efficiency of the pump.

When the torque enhancing function of the inverter is employed, according to Ref. [29], the starting torque of the electric motor can be written as Eq. (4):

$$
T_{\mathrm{m}}=\frac{c \cdot R_{2}^{\prime} \cdot\left(U_{0}+k f_{1}\right)^{2}}{50^{2} R^{2} f_{1}+X^{2} f_{1}^{3}}
$$

where $c=50^{2} m_{1} y / 2 \pi, k=\left(U_{\mathrm{e}}-U_{0}\right) / 50, R=R_{1}+R_{2}$, $X=2 \pi \cdot 50\left(L_{1}+L_{2}\right), R_{1}$ and $R_{2}$ are the stator and the transferred rotor resistances respectively, and $R$ is their sum. $L_{1}$ and $L_{2}$ are the stator and the transferred rotor leakage inductance respectively. $X_{1}, X_{2}$ and $X$ are respectively the stator, the transferred rotor inductive reactance and their sum. $m_{1}$ is the phase number, $y$ the number of the pole pairs, and $f_{1}$ the fundamental frequency. $U_{\mathrm{e}}$ is the rated input voltages in $\mathrm{V}$ respectively, $U_{0}$ the enhancing voltage when $f_{1}$ tends to $0 \mathrm{~Hz}$.

From Eqs. (1)-(4), the dynamic response of the electrohydraulic power source is depended on many factors. When the load condition and power supply capability are taken into account, it is difficult to describe the dynamic response. Thus, a test system is constructed to study the dynamic characteristic of the electro-hydraulic power source, as shown in Figure 2.
As shown in Figure 2, the electronic proportional pressure and flow pump is driven by an inverter motor. An electric proportional relief valve is used to load the system. And an accumulator is introduced to the system for auxiliary starting and braking. The pump can suction oil from the tank through the check valve or from the accumulator through the solenoid valve. The pump outlet and accumulator oil port are equipped with pressure sensors to detect the pressure of system. The pump outlet is equipped with flow meter also. In order to detect the electric power input of inverter motor, electric power meter is installed before and after the inverter. The ds1103 is used for controlling and signals acquisition.

\subsubsection{Dynamic Response of Electro-hydraulic Power Source}

Speed variable power source often starts with full load or heavy load, and sometimes its dynamic response may not meet the system requirements. With the system shown in Figure 2, the dynamic characteristics of the power source under different load condition are studied. The flow output of the pump is detected to characterize the dynamic response.

During test process, the initial motor speed is set as $0 \mathrm{r} / \mathrm{min}$, and the maximum starting current of the motor can be limited by the frequency converter. The pump pressure setting is set as $25 \mathrm{MPa}$ under which the pump will work at the maximum displacement. And the load pressure controlled by the loading valve is set as $0 \mathrm{MPa}$, $6 \mathrm{MPa}, 12 \mathrm{MPa}, 18 \mathrm{MPa}$. The speed control signal is set

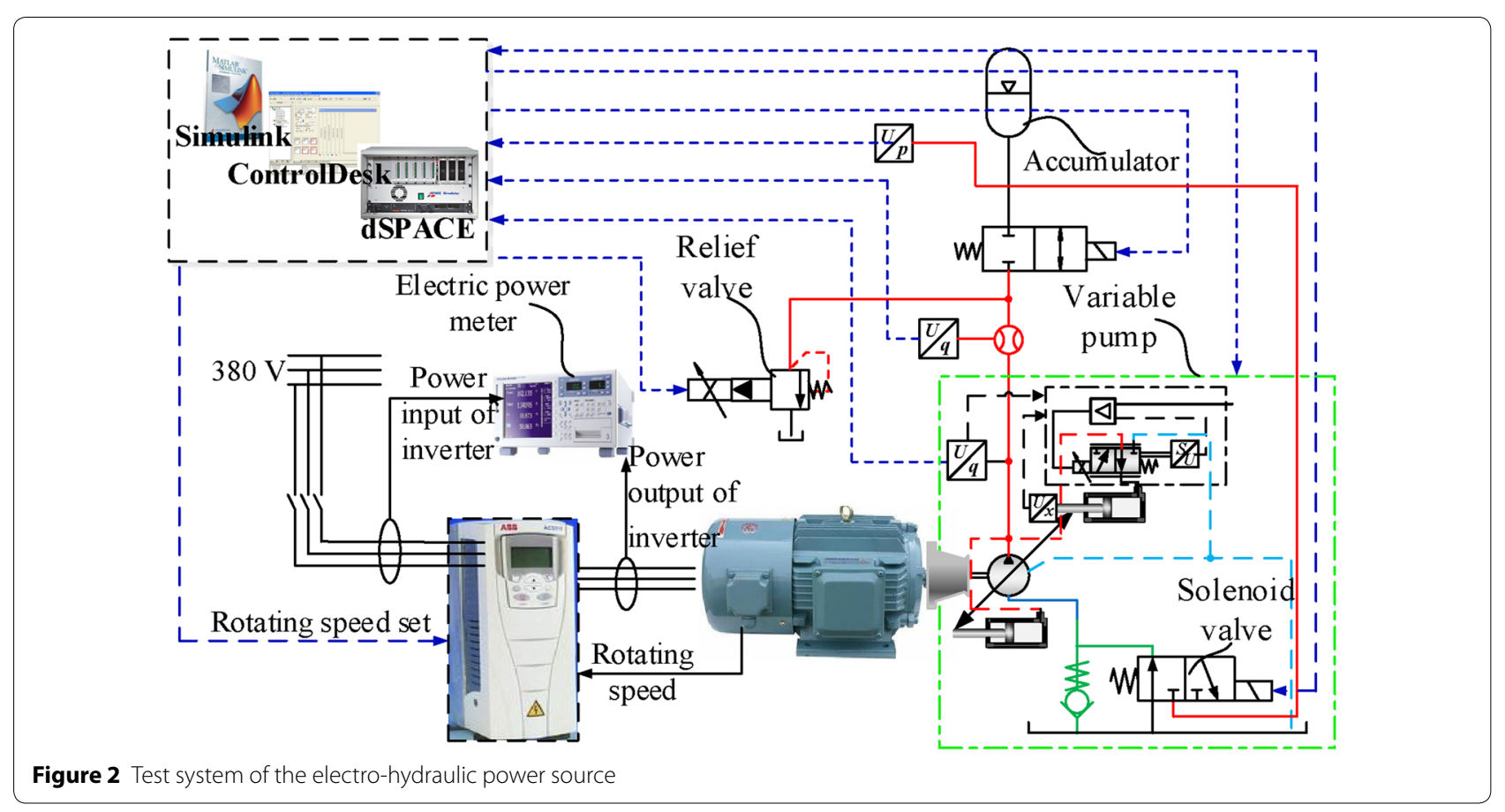


as $10 \mathrm{~V}$ by the step signal, at $1 \mathrm{~s}$. The experiment results are shown in Figure 3.

As shown in Figure 3(a), under rated current of the motor, with the increase of the load pressure, the starting time of the electro-hydraulic power source becomes longer, but the braking time becomes shorter. When the load pressures are $0 \mathrm{MPa}$ and $18 \mathrm{MPa}$, the starting times are about $0.58 \mathrm{~s}$ and $1.43 \mathrm{~s}$, and braking times are about $2.62 \mathrm{~s}$ and $0.66 \mathrm{~s}$. As shown in Figure 3(b), when the maximum starting current is set to 1.5 times of the rated current, the starting time increases with the load pressure, and the braking time decreases. It can be concluded that, under the 1.5 times of rated starting current, the increasing of the load pressure has less influence on the dynamic characteristics. And the starting time can meet the requirement of the excavator.

\subsubsection{Dynamic Characteristics of Pump}

The pump used in the system is an electrohydraulic axial piston variable displacement pump whose pressure and flow can be continuously adjusted. And also, benefitted from the feedback of the actual swivel angle and pressure, the controller can be designed to meet flow, pressure and power demand in proportion. The acquired actual values are processed in the amplifier and compared with the given command values.

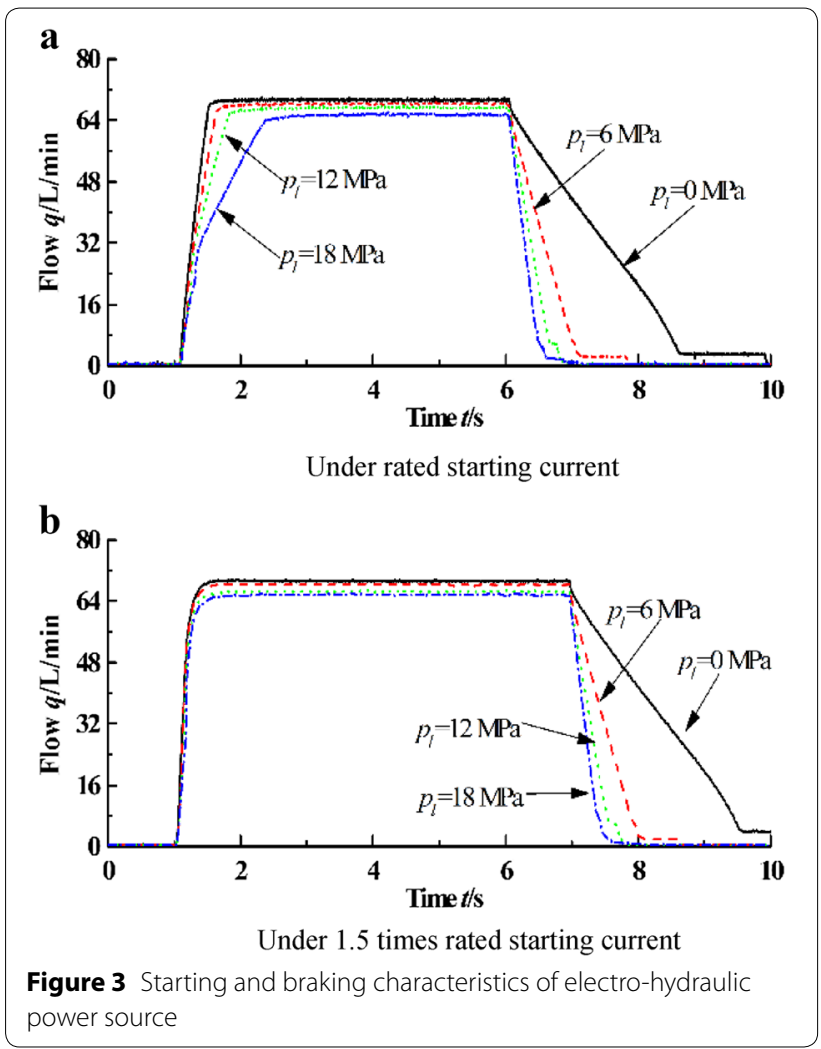

The dynamic characteristics test of this electrohydraulic displacement variable pump is conducted under a rotating speed of $1500 \mathrm{r} / \mathrm{min}$, the hydraulic volume connected to the pump outlet port for $1 \mathrm{~L}$ and the load pressure for $5 \mathrm{MPa}$. Figure 4 gives the dynamic response of the pump when the pump is set as a flow control model. The response time is $70 \mathrm{~ms}$ for $100 \%$ signals up and $29 \mathrm{~ms}$ for down. It can be concluded that the results show the pump has quicker dynamic response than the electric motor. Thus, its dynamic characteristic can be ignored in the electrohydraulic power source.

\subsection{Energy Efficiency of the Electro-hydraulic Power Source}

During the working process of electro-hydraulic power source, the energy conversion process of power source system is about frequency converter-electric motor-pump. The energy efficiency of the power source changing with the speed, pressure and flow. The main purpose of this paper is to design an efficient electro-hydraulic power source for mobile machine to improve its energy efficiency.

\subsubsection{Electric Motor}

For an asynchronous electric motor, the efficiency of the motor is within acceptable range when working under rated load of more than $50 \%$. And, usually the highest efficiency is achieved under the $75 \%$ of the rated load. Its efficiency tends to decrease dramatically below about $50 \%$ of the rated load. According to the structure and working principle of motor, the losses consist copper losses, iron losses and mechanical losses. The copper losses are mainly caused by the ohmic resistance of the copper coils, and it is affected by the load and current, and it can be written as Eq. (5):

$$
\Delta P_{C u}=m I^{2} R,
$$

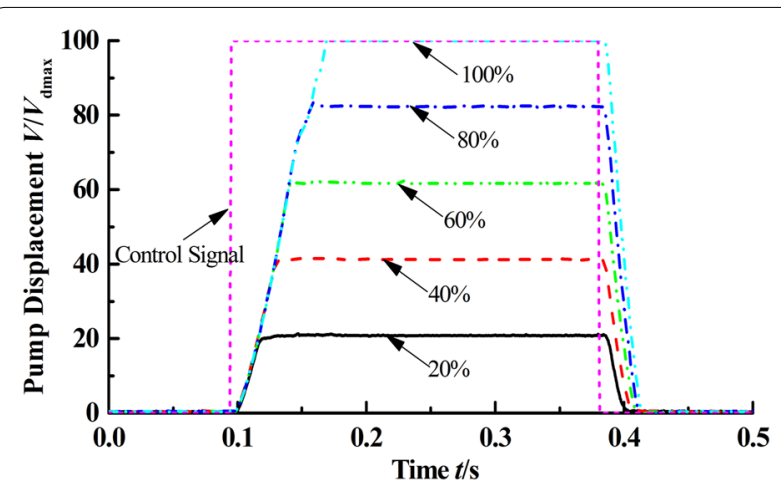

Figure 4 Pump displacement response under command value step condition 
where $m$ is motor phase number, $I$ represents phase current, $R$ represents ohmic resistance of the copper coils.

The iron losses are mainly caused by magnetizing losses and eddy-current losses in the stator, it can be written as Eq. (6):

$$
\Delta P_{F e}=\Delta P_{F \mathrm{e} 1}+\Delta P_{F \mathrm{e} 2}=k_{1} f_{1} B^{2}+k_{2} f_{1}^{2} B^{2},
$$

where $\Delta P_{\mathrm{Fe} 1}$ is magnetizing losses, $\Delta P_{\mathrm{Fe} 2}$ is eddy-current losses, $k_{1}, k_{2}$ are the iron losses coefficients, $f_{1}$ is the flux frequency, $B$ is flux density.

Mechanical losses are mainly friction losses and cooling, it can be written as Eq. (7):

$$
\Delta P_{m}=\Delta P_{\mathrm{f}}+\Delta P_{\mathrm{fan}},
$$

where $\Delta P_{\mathrm{f}}$ is friction losses, $\Delta P_{\mathrm{fan}}$ wind pressure of the fan.

Assuming that the output power of electric motor is $P_{2}$, the energy efficiency of the motor can be written as Eq. (8):

$$
\eta=\frac{P_{2}}{P_{2}+\Delta P_{F e}+\Delta P_{C u}+\Delta P_{m}+\Delta P_{\Delta}} .
$$

\subsubsection{Axial Piston Pump}

For speed and displacement variable pump, the flow rate output of the pump can be changed by adjusting the speed or the displacement of the pump, and the flow output of the pump can be calculated as Eq. (9):

$$
q_{\mathrm{p}}=n \cdot \beta \cdot V_{\max } \cdot \eta_{\mathrm{v}}
$$

The hydraulic pump losses consist volumetric and hydro-mechanical loss, and it can be written as Eq. (10):

$$
\eta_{\mathrm{p}}=\eta_{\mathrm{v}} \cdot \eta_{\mathrm{m}}
$$

According to Ref. [30], the experience calculation equation of the volumetric efficiency $\eta_{\mathrm{v}}$ and the mechanical efficiency $\eta_{\mathrm{m}}$ of the hydraulic pump can be written as Eqs. (11), (12):

$$
\begin{aligned}
& \eta_{\mathrm{v}}=1-\frac{k C_{\mathrm{s}} \Delta p}{\mu n \beta V_{\max }}, \\
& \eta_{\mathrm{m}}=\frac{1}{1+\frac{\mu n C_{\mathrm{s}}}{k C_{\mathrm{V}} \Delta p \beta}+\frac{C_{\mathrm{f}}}{\beta}+\frac{2 \pi T_{\mathrm{s}}}{\Delta p n \beta V_{\max }}},
\end{aligned}
$$

where $n$ is the rotating speed of pump, $k$ is the scale coefficient, $C_{\mathrm{s}}$ is leakage coefficient, $\Delta p$ is pressure difference, $\mu$ is kinematic viscosity, $C_{\mathrm{V}}$ is resistance coefficient of laminar, $C_{\mathrm{f}}$ is mechanical resistance coefficient, $T_{\mathrm{s}}$ is the torque losses independent of speed and pressure difference.
Figure 5 gives the overall efficiency of the pump varies with speed and displacement under 0.5 times rated pressure, calculated with Eqs. (11), (12).

It can be concluded that the larger the output flow rate of the pump, the higher the efficiency of the pump, for a certain pump. In addition, the shape of the flow contours and energy efficiency contours are basically the same. Thus, we can conclude that the changing the speed or displacement have less influence on the overall efficiency under a certain flow rate requirement condition. However, for the hydraulic pump, its efficiency is affected by pressure, temperature, rotating speed, and so on. Thus, it is difficult to forecast relationship of these parameters with the energy efficiency of the pump. According to the Ref. [31], the loss of displacement-controlled pump presented is similar to the theoretical analysis in this paper. Thus, the theoretical data can be used for guiding the control strategy design in this paper.

\subsubsection{Electro-hydraulic Power Source}

According to analysis, the energy efficiency of the electro-hydraulic power source is affected by many parameters, such as speed, displacement, pressure and so on. In order to validate the results of theoretic analysis about the energy efficiency of the electric motor and pump, the energy efficiency of the electro-hydraulic power source is tested based on the test system shown in Figure 2. The rated nominal output power and speed of the electric motor are $37 \mathrm{~kW}$ and $1500 \mathrm{r} / \mathrm{min}$ respectively. And, the rated displacement of the pump is about $71 \mathrm{~mL} / \mathrm{r}$. Changing the load pressure, speed and displacement of the pump, we can get the energy efficiency curves of the electro-hydraulic power source under different conditions, as shown in Figure 6.

As shown in Figure 6, the energy efficiency of the electro-hydraulic power source increases with the load power increasing. And, according to the tested results, When

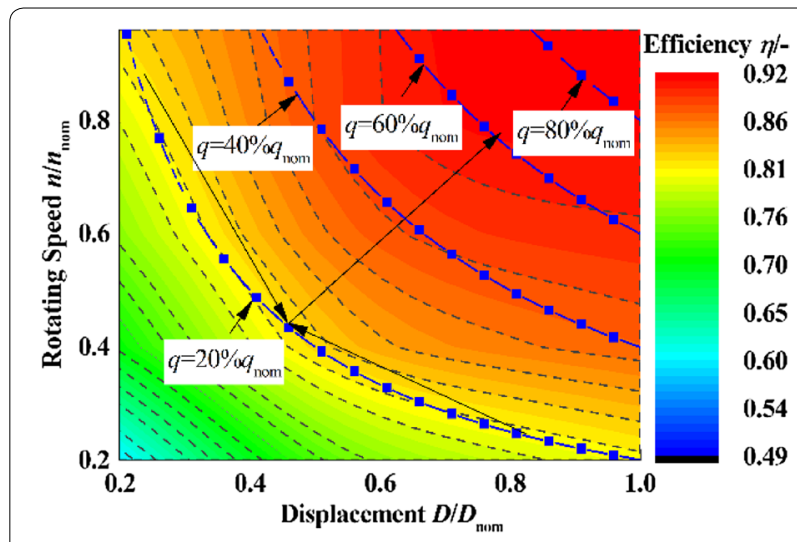

Figure 5 Overall efficiency of the pump 


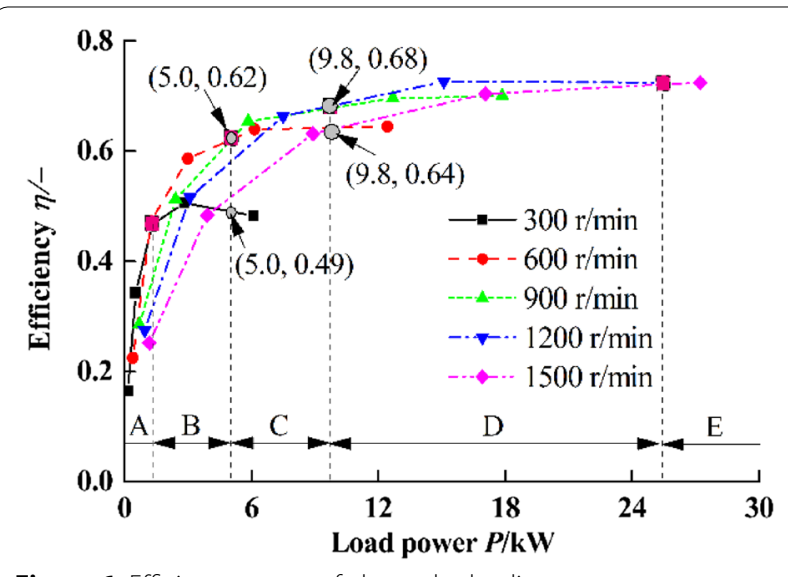

Figure 6 Efficiency curves of electro-hydraulic power source

the load power is given, we can find an efficient speed set value. For example, when the load power is about $5 \mathrm{~kW}$, the energy efficiencies under $300 \mathrm{r} / \mathrm{min}, 600 \mathrm{r} / \mathrm{min}, 900 \mathrm{r} /$ $\mathrm{min}, 1200 \mathrm{r} / \mathrm{min}$ and $1500 \mathrm{r} / \mathrm{min}$, are $49.0 \%, 62.0 \%, 62.6 \%$, $57.8 \%$ and $51.8 \%$ respectively. Thus, in the practical application, the power source efficiency can be improved by detecting the load power to change the speed of the power source.

\subsection{Dynamic Response Improvement of the Power Source}

As mentioned in Section 3.1, when the motor starting current is large enough, the dynamic response of the system basically meets the needs of use, but it may cause a big impact on the grid. Therefore, an accumulator is introduced to the system to improve the dynamic response. Figure 7 gives the dynamic response of the system under the condition that accumulator filling pressure is about $18 \mathrm{MPa}$, loading pressure is set as $21 \mathrm{MPa}$ and the current is limited to rated current. During the experiment process, a speed control signal of $10 \mathrm{~V}$ is given at $1 \mathrm{~s}$, and at a time of $7 \mathrm{~s}$ the control signal step is decreased to $0 \mathrm{~V}$. As shown in Figure 7, when the load pressure is about $21 \mathrm{MPa}$, the starting time is about $2.36 \mathrm{~s}$. And it can be shortened to $0.58 \mathrm{~s}$ with the accumulator assistant. And also, the starting power demand can be decreased, as well as the braking time.

\section{Control Strategy of Electric Excavator}

During the working process of the excavator, the operator gives the velocity control signal through the joystick, the swivel of the joystick is proportional to the velocity of the hydraulic actuator. If there is only one actuator, it is easy to realize the velocity control of the actuator by controlling the output flow of the pump. When there are more than one actuators working simultaneously, it is necessary to control the flow distribution ratio besides
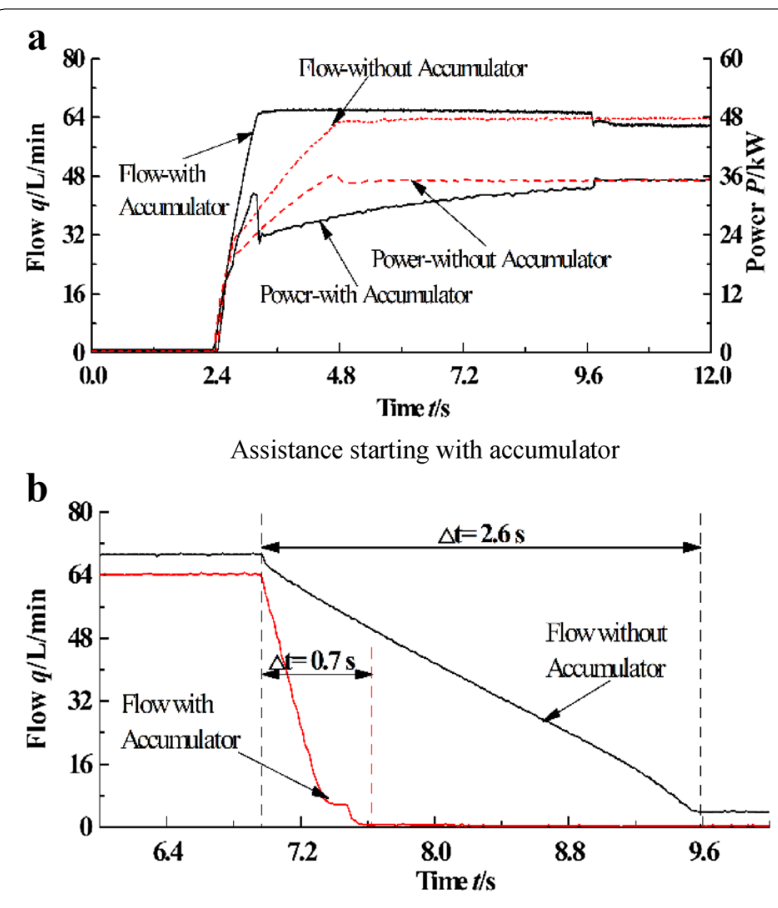

Assistance braking with accumulator

Figure 7 Performance of the starting and braking with accumulator auxiliary

controlling the output flow of the pump. Thus, the control strategy of electric excavator consists of demand flow calculation, power source control and flow distribution modules, as shown in Figure 8.

\subsection{Flow Calculation Module}

Figure 9 gives the principle of flow calculation module. During working process, the operator gives the velocity control signal $v_{\mathrm{d}}$ through a joystick, the controller calculates the demand flow $q_{\mathrm{d}}$. If the aggregate demand flow $q_{\mathrm{da}}$ is greater than that the power source can supply, the demand flow rates of every working actuators are rebuilt to realize flow-saturated resistant. And then the aggregate demand flow $q_{\mathrm{da}}$ and demand flow rates such as $q_{1}$, $q_{2}$ are delivered to power source and flow distribution module.

Take compound action of two cylinders for example, the operator gives the velocity control signal $v_{\mathrm{d} 1}$ and $v_{\mathrm{d} 2}$, and they are translated to the flow signals of the corresponding cylinders $q_{\mathrm{d} 1}$ and $q_{\mathrm{d} 2}$, if the aggregate demand flow $q_{\mathrm{da}}<q_{\mathrm{max}}$, the $q_{\mathrm{da}}$ is delivered to power source, and $q_{1}$ and $q_{2}$ are delivered to the flow distribution modules. if the aggregate demand flow $q_{\mathrm{da}}>q_{\mathrm{max}}$, the $q_{\max }$ is delivered to power source, and $q_{1}$ and $q_{2}$ are calculated as Eq. (13): 


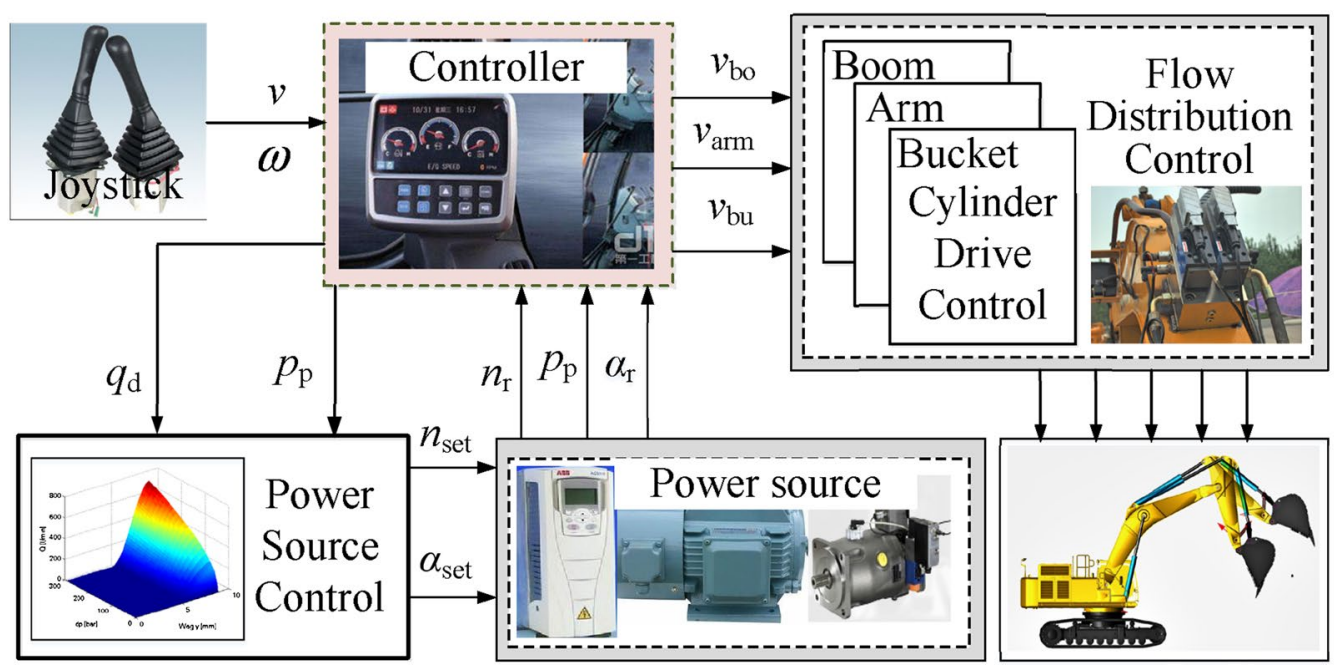

Figure 8 System architecture for excavator

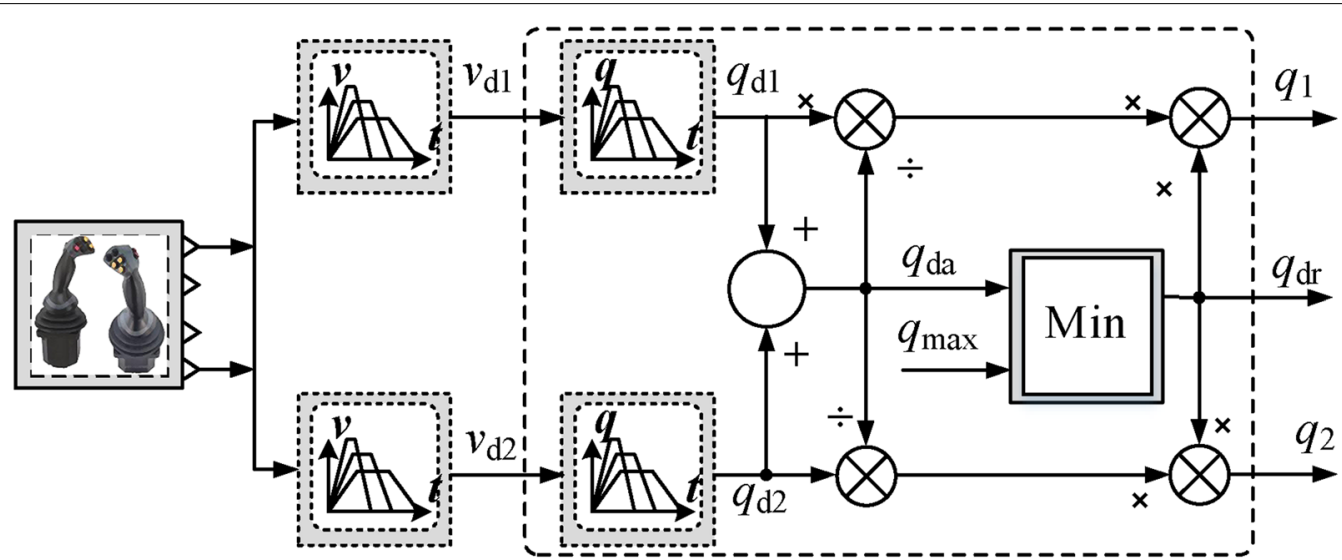

Figure 9 Principle of flow calculation module

$$
\left\{\begin{array}{l}
q_{1}=\frac{q_{\mathrm{d} 1}}{q_{\mathrm{d} 1}+q_{\mathrm{d} 2}} q_{\mathrm{max}} \\
q_{2}=\frac{q_{\mathrm{d} 2}}{q_{\mathrm{d} 1}+q_{\mathrm{d} 2}} q_{\mathrm{max}}
\end{array}\right.
$$

\subsection{Power Source Module}

The power source module' job is to control the speed and displacement of the pump, according to the signal $q_{\mathrm{dr}}$. The aim of this module is to ensure the dynamic performance while improving the energy efficiency and to reduce the operating costs. The control principle is that, while the flow changes rapidly, it is necessary to avoid changing the motor speed, and when the load power is relatively low, the speed motor is set as a low value to achieve a good efficiency. Thus, a matching method based on the segmented speed control and continuous displacement control of the pump is proposed, as shown in Figure 10.

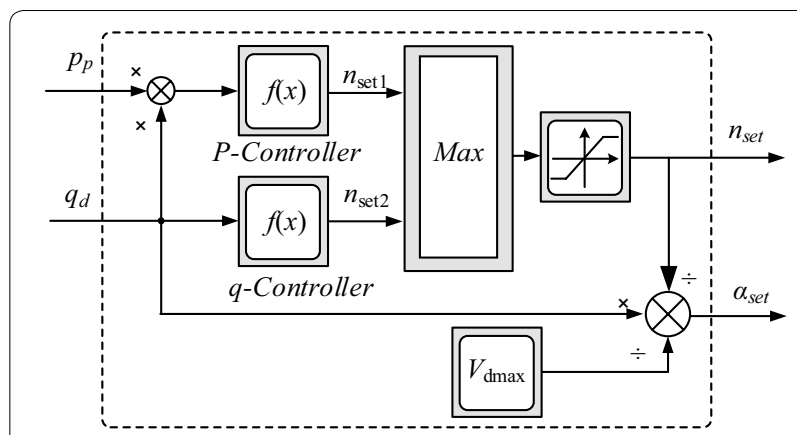

Figure $\mathbf{1 0}$ Coordinated control of rotational speed and displacement

As shown in Figure 10, according to $q_{\mathrm{d}}$, the speed of the motor $n_{\text {set } 1}$ is calculated when the displacement of the pump is set as $80 \%$ rated displacement; and then 
according to $q_{\mathrm{d}}$ and the pump's outlet pressure $p_{\mathrm{p}}$, the load power $P_{\mathrm{p}}$ can be calculated out, the table look up method is used to determine the speed $n_{\text {set2 }}$ under which the electro-hydraulic power source works under high efficiency; and then the maximum value of these two speeds are chosen to control the motor.

When the speed of the motor is determined, the displacement of the pump can be calculated according to Eq. (14):

$$
V=\frac{q_{\mathrm{d}}}{n_{\mathrm{set}}} .
$$

\subsection{Flow Distribution Module}

The flow distribution module' job is to distribute the output flow of the pump by changing the opening levels of control valves. The control principle is shown in Figure 11.

As shown in Figure 11, the control model can be divided into open circuit pump control, metering out control, metering in control, regeneration control and metering in and metering out control, according to the direction of the load and velocity. When the actuator works under resistance load, the open circuit pump control is selected to reduce throttling loss by fully opening the control valves. When the actuator works under over-running load, the metering out control and regeneration control are selected. And when there are more than one actuators working simultaneously, the metering in control method is used to control the actuator which works under low load, and also when this actuator works under over-running load, the metering in and metering out control method is used.

Take cylinder extension as an example, firstly, the load condition of this cylinder can be determined by the cylinder pressures, and then the control model and ratio coefficients $k_{\mathrm{A}}$ and $k_{\mathrm{B}}$ can be identified, at last, the inlet and outlet flow rates are calculated to control the valves based on the basis of feedback of pressure difference.

\section{Experiment and Results Analysis}

\subsection{Experiment Rig}

In this paper, a 6-ton hydraulic excavator is chosen as the test rig, as shown in Figure 12. Firstly, the diesel engine is removed and an electric motor whose rated power is $37 \mathrm{~kW}$ is installed. And, the independent metering in and

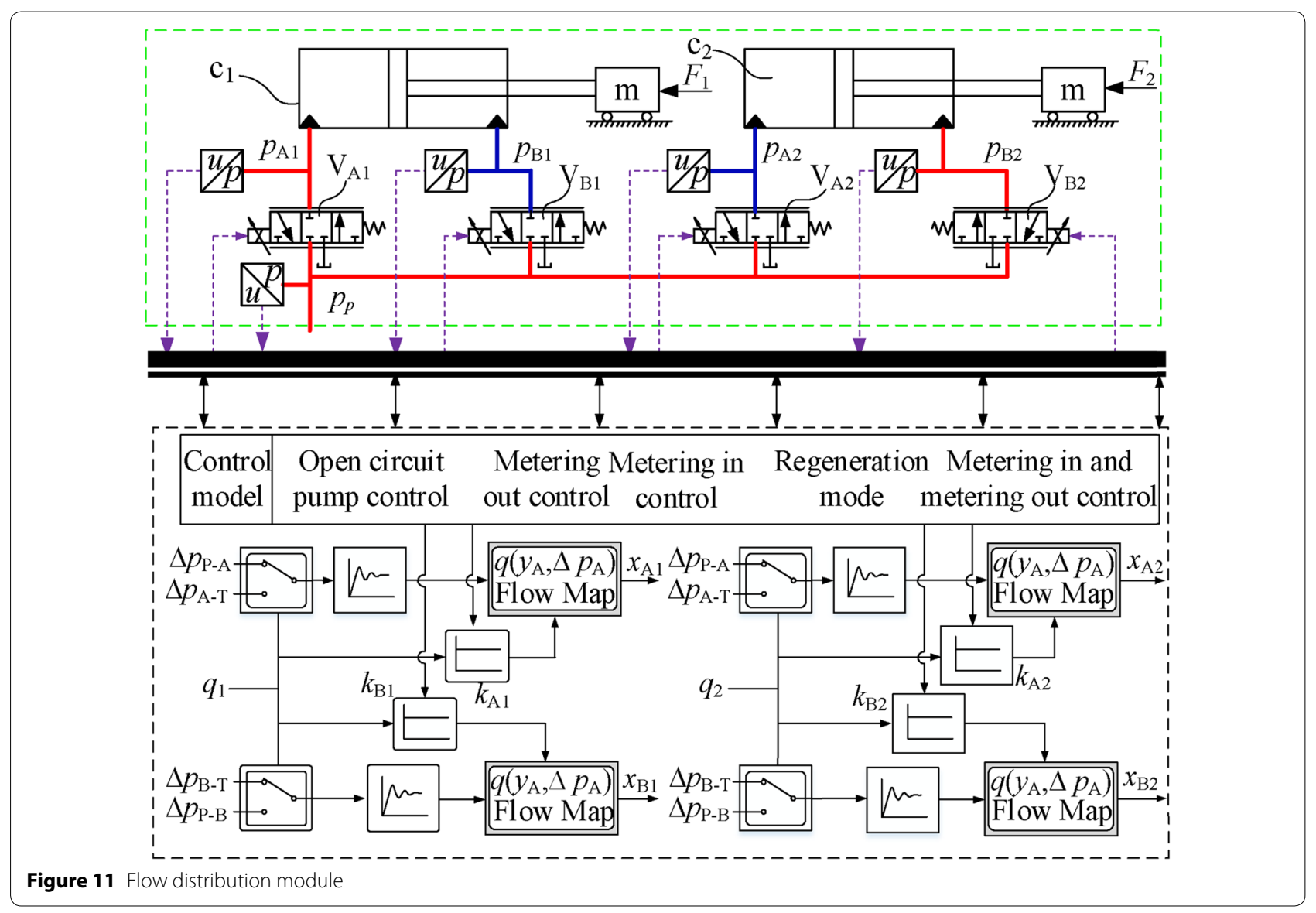




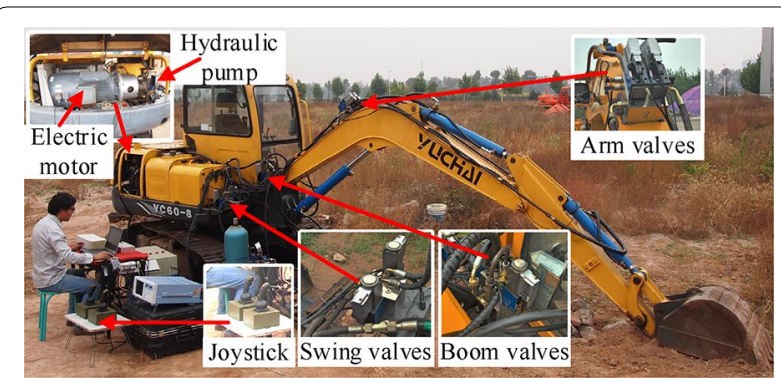

Figure 12 Test Rig

metering out system is used to reduce the throttling loss. The working performance and energy efficiency of the single actuator, such as the boom cylinder, arm cylinder and bucket cylinder are tested under the same working condition with the proposed speed and displacement coordination method and a traditional displacement variable method. The speed of the traditional displacement variable method is set as $1500 \mathrm{r} / \mathrm{min}$.

\subsection{Experiment Results}

\subsubsection{Boom Cylinder}

Figures 13, 14, 15, 16 present the experimental results of the speed of the motor, actual swivel of the pump, outlet pressure of the pump, the electric power input to the system and the displacement of the boom cylinder. When the boom cylinder extends out, the flow is set as the demand, and pump does not output flow at other times. When the boom cylinder retracts in, the two control valves are connected to the tank, and the boom retracts due to its gravity.

5.2.1.1 High velocity As shown in Figures 13 and 14, the demand flow is set as $50 \mathrm{~L} / \mathrm{min}$. At the time of $1.4 \mathrm{~s}$, the operator gives the extending velocity demand signal

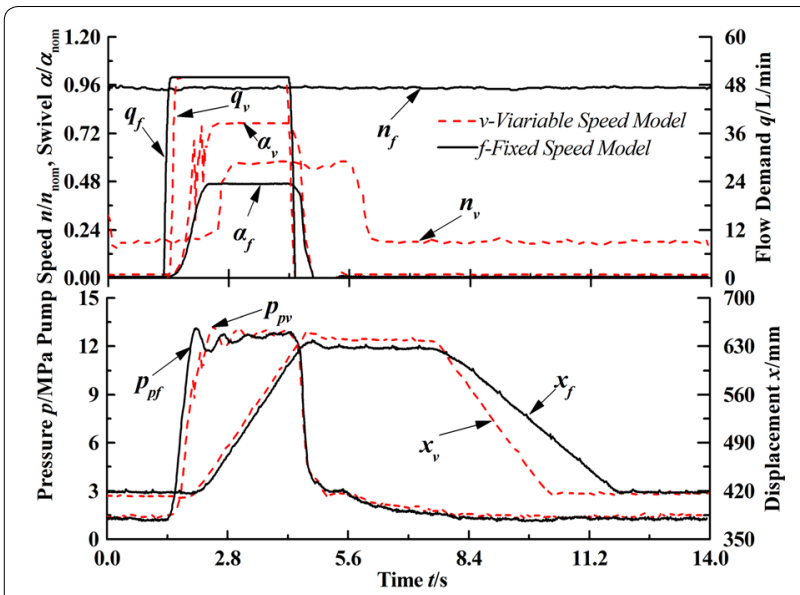

Figure 13 Actual speed and swivel of the pump

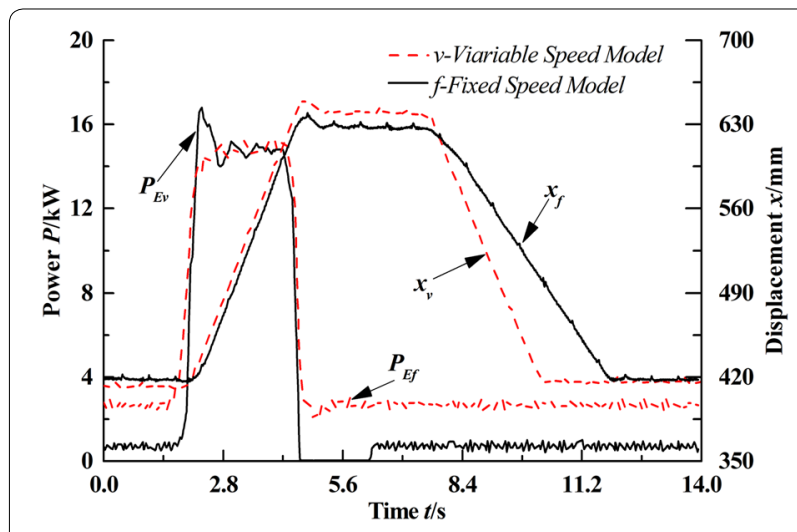

Figure 14 Electric power input and displacement of the cylinder

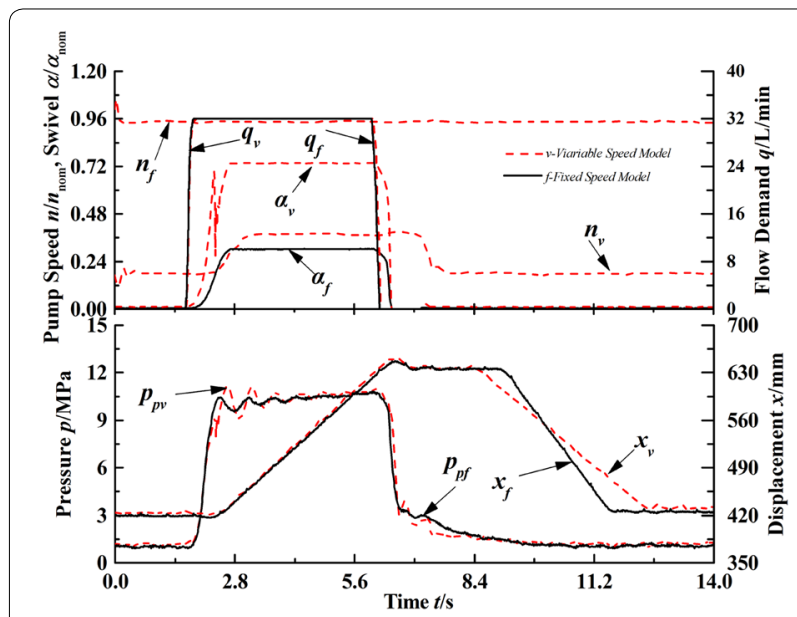

Figure 15 Actual speed and swivel of the pump

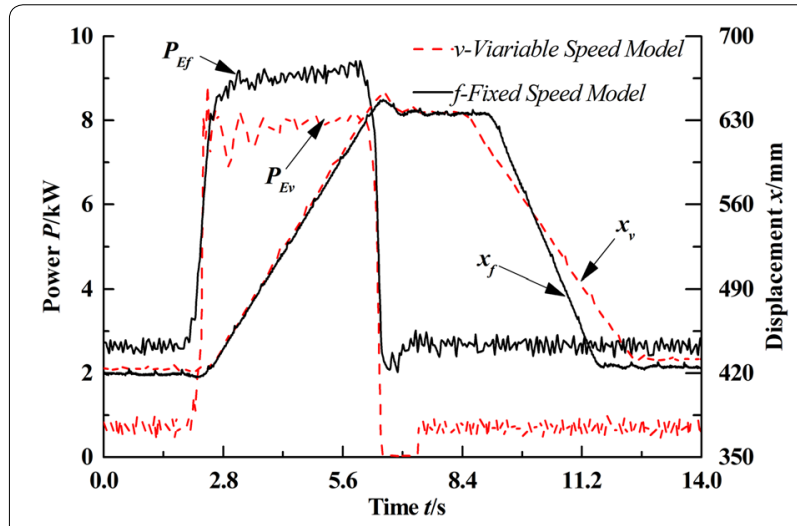

Figure 16 Electric power input and displacement of the cylinder

by operating the joystick. The electric motor and pump work under the set signals. And at the time of $4.2 \mathrm{~s}$, the operator releases the joystick, the electric motor works under a speed of $300 \mathrm{r} / \mathrm{min}$, and the displacement of the 
pump is set as its minimum. At the time of $7.6 \mathrm{~s}$, the operator gives the retraction signal, and the boom cylinder retracts under a regeneration model.

As shown in Figure 13, under the same flow rates, the speed and swivel of the pump are about $1500 \mathrm{r} / \mathrm{min}$ and $46 \%$ with the constant speed strategy, and which are about $900 \mathrm{r} / \mathrm{min}$ and $77 \%$ with the new designed coordination method. From the pressure and displacement curves, it can be seen that the dynamic performances are approximately equal.

As shown in Figure 14, when the boom cylinder extends out, the electric power consumptions with the two methods are almost the same, which is about $14.84 \mathrm{~kW}$, and the energy efficiency of the power source is about $67.3 \%$.

However, when the pump does not output flow, the power consumption is about $2.67 \mathrm{~kW}$ with the constant speed strategy, and which is only $0.62 \mathrm{~kW}$ with the new designed method. It can be obtained that the electric power consumption at idle can be effectively reduced.

5.2.1.2 Medium velocity As shown in Figures 15 and 16 , the demand flow is set as $30 \mathrm{~L} / \mathrm{min}$. At the time of $1.7 \mathrm{~s}$, the operator gives the extending velocity demand signal by operating the joystick. The electric motor and pump work under the set signals. And at the time of $6 \mathrm{~s}$, the operator releases the joystick, the electric motor works under a speed of $300 \mathrm{r} / \mathrm{min}$, and the displacement of the pump is set as its minimum.

As shown in Figure 15, under the same flow rates, the speed and swivel of the pump are about $1500 \mathrm{r} / \mathrm{min}$ and $29 \%$ with the constant speed strategy, and which are about $600 \mathrm{r} / \mathrm{min}$ and $71 \%$ with the new designed coordination method. From the pressure and displacement curves, it can be seen that the dynamic performances are approximately equal.

As shown in Figure 16, when the boom cylinder extends out, the electric power consumptions with the constant speed method is $9.12 \mathrm{~kW}$, which is $7.75 \mathrm{~kW}$ with the new coordination method, and the energy efficiencies of the power source are about $57.6 \%$ and $67.8 \%$. It can be obtained that the electric power consumption under partial load can be effectively reduced.

\subsubsection{The Whole Machine Working}

Figure 17 gives the displacements of the cylinders and electric power input to the system, when the whole machine works under non-load condition. During 2.12-4.75 s, the boom cylinder extends out with the flow rate about $50 \mathrm{~L} / \mathrm{min}, 8.79-12.67 \mathrm{~s}$, the arm cylinder extends out with the flow rate about $50 \mathrm{~L} / \mathrm{min}$, 15.05-19.61 s, the arm cylinder retracts in with the flow rate about $30 \mathrm{~L} / \mathrm{min}, 23.45-26.99 \mathrm{~s}$, the bucket

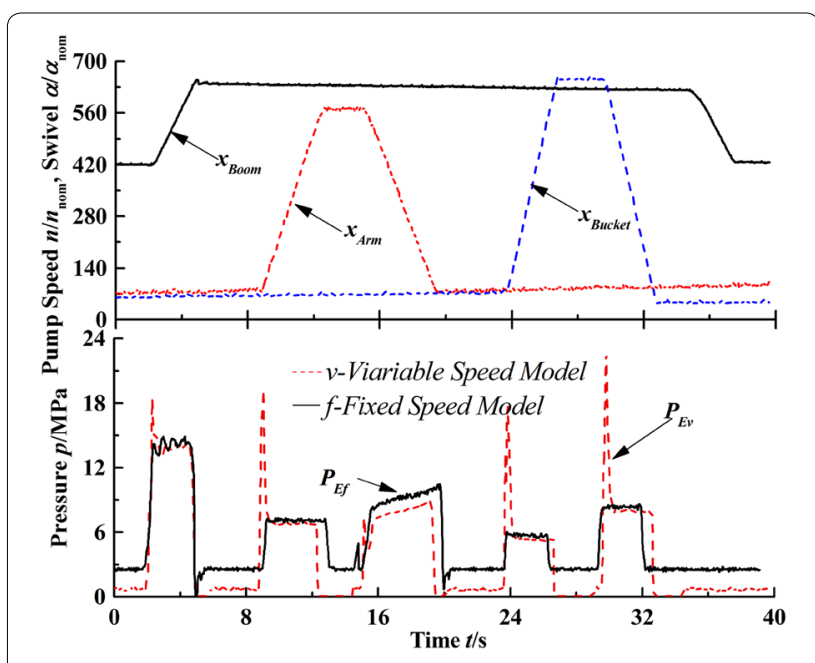

Figure 17 Electric power input and displacement of the cylinders

cylinder extends out with the flow rate about $50 \mathrm{~L} / \mathrm{min}$, 29.51-32.85 s, the bucket cylinder retracts in with the flow rate about $30 \mathrm{~L} / \mathrm{min}$, and then $34.77-37.54 \mathrm{~s}$, the boom cylinder retracts in under the regeneration model.

When the boom cylinder extends out, the arm cylinder extends out and retracts in, the bucket cylinder extends out and retracts in, the energy efficiency of the power source with the constant speed method are as follows $67.3 \%, 48.3 \%, 61.2 \%, 39.5 \%$ and $58.2 \%$, and which are about $70.3 \%, 52.5 \%, 71.5 \%, 43.2 \%$ and $62.6 \%$ with the new coordination method.

\section{Conclusions}

(1) During most working conditions, the lowest and highest energy efficiency of the power source driven by an electric motor are $43 \%$ and $71 \%$, which is significantly higher than the power source with a fuel engine. And also, using the new coordination method, the energy efficiency can be increased about 3\%-10\%.

(2) During the idle period, the motor speed is set as $300 \mathrm{r} / \mathrm{min}$ and the power source output a constant pressure about $1.5 \mathrm{MPa}$, the power consumption is about $0.62 \mathrm{~kW}$ with the new coordination method, and which is about $2.67 \mathrm{~kW}$ with the constant speed method.

(3) When the electric motor starts with full load or heavy load, the dynamic response of the power source is relatively slow. However, the dynamic response of the system can be improved to meet the needs of use with the segmented speed control and continuous displacement control and an accumulator. 


\section{Authors' Contributions}

LG was in charge of the whole trial and wrote the manuscript; LQ guided the writing of the manuscript. XZ, ZD and JY assisted with sampling and laboratory analyses. All authors read and approved the final manuscript.

\section{Authors' Information}

Lei Ge, born in 1987, is currently a postdoctoral at Taiyuan University of Technology, China. He received his PhD degree from Taiyuan University of Technology, China. His research interests include power matching of electro-hydraulic power source, energy saving of mobile machinery.

Long Quan, born in 1959, is currently a professor at Key Lab of Advanced Transducers and Intelligent Control System of Ministry of Education, Taiyuan University of Technology, China. His research interests include electro-hydraulic control system and hydraulic excavator.

Xiaogang Zhang, born in 1964, is currently an associate professor at Taiyuan University of Technology, China.

Zhixin Dong, born in 1984, is currently a PhD candidate at Taiyuan University of Technology, China.

Jing Yang, born in 1972, is currently an associate professor at Taiyuan University of Technology, China.

\section{Competing Interests}

The authors declare that they have no competing interests.

\section{Funding}

Supported by National Natural Science Foundation of China (Grant Nos. 51575374, U1510206).

Received: 15 February 2019 Accepted: 6 November 2019 Published online: 04 December 2019

\section{References}

[1] M Ochiai, S Ryu. Hybrid in construction machinery. Proceedings of the 7th JFPS International Symposium on Fluid Power, Toyama, Japan, September 15-18, 2008: 41-44.

[2] J Lodewyks, P Zurbrügg. Decentralized energy-saving hydraulic concepts for mobile working machines. 10th International Fluid Power Conference, Dresden, Germany, March 8-10, 2016: 79-90.

[3] B S Yoo, J Cho, C M Hwang, et al. Development of a simulation program for conceptual design of hybrid excavators. SICE Annual Conference, Tokyo, Japan, September 13-18, 2011: 318-322.

[4] Y Gao, P E Feng, B Peng, et al. Stage-based power matching control of hydraulic excavator. Journal of Harbin Engineering University, 2017, 38(9): 1461-1469. (in Chinese)

[5] S P Yang, H Yu, J G Liu. Research on power matching and energy saving control of power system in hydraulic excavator. Journal of Mechanical Engineering, 2014, 50(05): 152-160. (in Chinese)

[6] J Yang, L Quan, Y Yang. Excavator energy-saving efficiency based on diesel engine cylinder deactivation technology. Chinese Journal of Mechanical Engineering, 2012, 25(5): 897-904.

[7] Y T Zhang, Q F Wang, Q Xiao, et al. Constant work-point control for parallel hybrid system with capacitor accumulator in hydraulic excavator. Chinese Journal of Mechanical Engineering, 2006, 19(4): 505-508.

[8] T S Kwon, SW Lee, S K Sul, et al. Power control algorithm for hybrid excavator with supercapacitor. IEEE Transactions on Industry Applications, 2010, 46(4): 1447-1455.

[9] H Kim, S Yoo, S Cho. Hybrid control algorithm for fuel consumption of a compound hybrid excavator. Automation in Construction, 2016, 68 $1-10$.

[10] T L Lin, W P Huang, H L Ren, et al. New compound energy regeneration system and control strategy for hybrid hydraulic excavators. Automation in Construction, 2016, 68: 11-20.

[11] T L Lin, Q F Wang. Hydraulic accumulator-motor-generator energy regeneration system for a hybrid hydraulic excavator. Chinese Journal of Mechanical Engineering, 2012, 25(6): 1121-1129.
[12] W Shen, J H Jiang, X Su, et al. Control strategy analysis of the hydraulic hybrid excavator. Journal of the Franklin Institute, 2015, 352(2): 541-561.

[13] W Shen, H Huang, Y Pang, et al. Review of the energy saving hydraulic system based on common pressure rail. IEEE Access, 2017, 5: 655-669.

[14] Q Y Hu, H Zhang, S J Tian, et al. Performances analysis of a novel loadsensing hydraulic system with overriding differential pressure control. Proceedings of the Institution of Mechanical Engineers Part C Journal of Mechanical Engineering Science, 2016, 231(23): 4331-4343.

[15] J Cho, J Lee. Simulation-aided testing of electro-hydraulic pump for excavator. Proceedings of the ASME/BATH 2015 Symposium on Fluid Power and Motion Control, Chicago, USA, October 12-14, 2015: 1-8.

[16] Y L Cho, D S Jang, KY Kim. Development of the energy efficient electro-hydraulic system for excavator. 7th International Fluid Power Conference, Aachen, Germany, March 22-24, 2010: 1-12.

[17] L Lu, B Yao, Energy-saving adaptive robust control of a hydraulic manipulator using five cartridge valves with an accumulator. IEEE Transactions on Industrial Electronics, 2014, 61(12): 7046-7054.

[18] W N Huang, L Quan, J H Huang, et al. Excavator swing system controlled with separate meter-in and meter-out method. Journal of Mechanical Engineering, 2016, 52(20): 159-167. (in Chinese)

[19] A Sitte, J Weber. Structural design of independent metering control systems. 13th Scandinavian International Conference on Fluid Power, Linköping, Sweden, June 3-5, 2013: 261-270.

[20] B Xu, R Q Ding, J H Zhang, et al. Pump/valves coordinate control of the independent metering system for mobile machinery. Automation in Construction, 2015, 57: 98-111.

[21] Z X Dong, W N Huang, L Ge, et al. Research on the performance of hydraulic excavator with pump and valve combined separate meter in and meter out circuits. Journal of Mechanical Engineering, 2016, 52(12): 173-180. (in Chinese)

[22] B Liu, L Quan, L Ge. Research on the performance of hydraulic excavator boom based pressure and flow accordance control with independent metering circuit. Proceedings of the Institution of Mechanical Engineers Part E Journal of Process Mechanical Engineering, 2016, 231(5): 901-913.

[23] J P Shi, L Quan, X G Zhang, et al. Electro-hydraulic velocity and position control based on independent metering valve control in mobile construction equipment. Automation in Construction, 2018, 94: 73-84.

[24] S Helduser. Electric-hydrostatic drive-an innovative energy-saving power and motion control system. Proceedings of the Institution of Mechanical Engineers, Part I: Journal of Systems and Control Engineering, 1999, 213(5): 427-437.

[25] L Quan, S Helduser. Energy saving and high dynamic hydraulic power unit based on speed variable motor and constant hydraulic pump. China Mechanical Engineering, 2003, 14(7): 606-609. (in Chinese)

[26] T A Minav, J J Pyrhonen, L E Laurila. Permanent magnet synchronous machine sizing: effect on the energy efficiency of an electrohydraulic forklift. IEEE Transactions on Industrial Electronics, 2012, 59(6): 2466-2474.

[27] Z Yan, L Quan, J H Huang. Characteristics of pulsation and noise in the axial piston pump with displacement and speed compound control. Journal of Mechanical Engineering, 2016, 52(16): 176-184. (in Chinese)

[28] K Roosen, R Bublitz. Energetic optimization of variable speed pump systems towards European Ecodesign directive. The 9th International Fluid Power Conference, Aachen, Germany, March 24-26, 2014: 123-133.

[29] X J Yang, X J Zhang, Y M Gong. Starting characteristics of motor in inverter-motor drive system. Journal of Shanghai University, 2000, 4(2): 140-144. (in Chinese)

[30] M Liu. The energy saving method based on conversion efficiency promoting of hydraulic pump and motor. Hefei University of Technology, 2015. (in Chinese)

[31] J Lux, H Murrenhoff. Experimental loss analysis of displacement controlled pumps. 10th International Fluid Power Conference, Dresden, Germany, March 8-10, 2016: 441-452. 